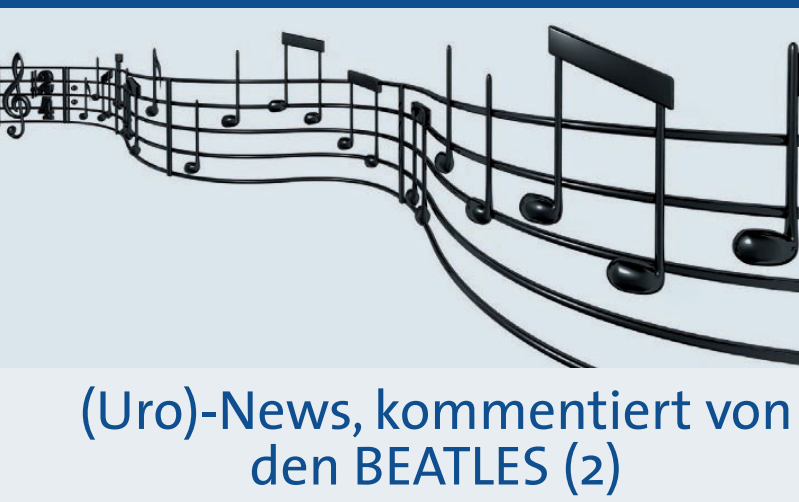

Offener Brief an Gesundheitsminister Rösler: „Please Mr Postman“

Betreuung von RVO-Patienten mit Uro-Ca ab 01.01.10 unklar: „Tomorrow Never Knows"

Verschlüsselung von Ca-Patienten als Geldquelle für die AOK:

„You Never Give Me Your Money“

Krankenkassen erzielen 1,4 Mrd. Euro Überschuss „Baby, You're A Rich Man“

Den Kassen werden 20104 Mrd. Euro fehlen "Cry Baby Cry“"

Privatversicherer wollen künftig weniger zahlen: „Fixing A Hole“

Rechnungshof rügt Gehälter der Kassenbosse: „I'm Looking Through You“

SPD warnt vor neuen Milliarden-Kosten im Gesundheitswesen:

"Twist and Shout"

Notorischer Steuersünder-Arzt verliert Approbation:

"Taxman“"

Schweinegrippe-Impfung skandalumwittert: „Piggies“

Beim Kaninchen funktioniert's:

\title{
Tissue-Engineering zur Penisrekonstruktion
}

— Penisverletzungen mit funktionellen Einschränkungen stellen die Rekonstruktionschirurgie vor heikle Probleme. Amerikanische Forscher vom Wake Forest Institute for Regenerative Medicine and Department of Urology in Winston, North Carolina, scheinen eine Lösung gefunden zu haben, die den Betroffenen wieder ein normales Sexualleben und eine ungestörte Miktion ermöglicht [Chen et al. PNAS, OnlineVorabpublikation; doi: 10.1073/ pnas.0909367106].

Das größte Problem bei der Penis-Rekonstruktion besteht darin, dass natives Penis-Gewebe nur in spärlicher Menge vorhanden ist. In vorangegangenen Versuchen ist es

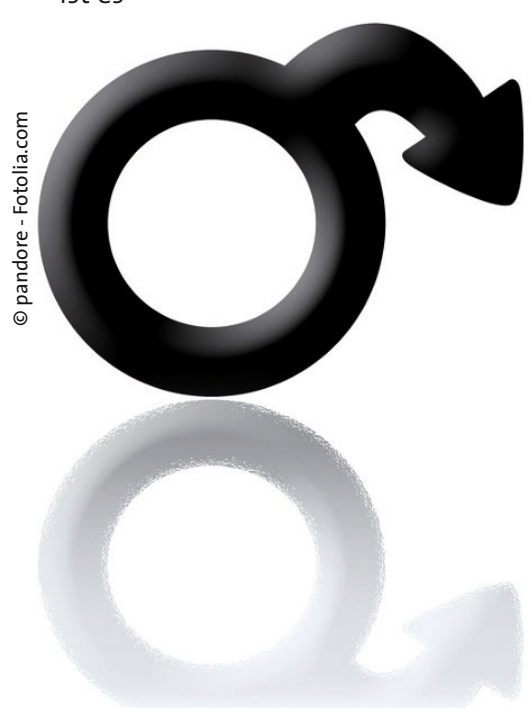

den Forschern bereits gelungen, kurze Schwellkörpersegmente durch eine kollagene Matrix mit autologen Zellen zu ersetzen. Im Tiermodell haben sie dies nun mit dem gesamten Schwellkörper von Kaninchen versucht - mit Erfolg. Die kavernöse Kollagenmatrix wurde mit autologen Zellen versetzt und nach einer schrittweisen Aufbereitung anstelle des exzidierten Schwellkörpers implantiert. Der biotechnologisch hergestellte Ersatz zeigte die gleichen strukturellen und funktionellen Fähigkeiten wie das Nativgewebe; männliche Kaninchen mit bilateralen Implantaten waren sogar dazu in der Lage, Nachwuchs zu zeugen.

Zwar sind noch viele weitere Studien nötig, bevor die Methode auch beim Menschen eingesetzt werden kann. Doch die Forscher sehen in dieser neuen Technologie ein beachtliches Potenzial für Patienten, die aufgrund von Anomalien, Trauma, Tumor oder Ähnlichem auf eine Penisrekonstruktion angewiesen sind.

dka

\section{Syphilitische Landflucht}

— Syphilis - die frühere „Geißel der Menschheit“ - sucht bevorzugt deutsche Großstädte heim und mutiert dabei zunehmend zur „Männerkrankheit“. So zählte man im Jahr 2008 in Berlin 44 Prozent Erkrankte mehr als im Vorjahr; in Hamburg stieg die Zahl der Syphilis-Fälle um rund ein Drittel an. Bundesweit wurden 2008 insgesamt 3.172 Syphilis-Erkrankungen gemeldet. Damit stag- nieren die Erkrankungszahlen insgesamt auf einem ähnlich hohen Niveau wie 2004. Diese Erkrankungslast ruht fast ausschließlich auf männlichen Schultern: Der Frauenanteil betrug 2008 nur rund sieben Prozent - der niedrigste Wert seit Einführung der geänderten Meldepflicht im Jahr 2001.

Die Epidemiologen des RKI sehen in der Syphilis heute vorwiegend ein Großstadtphä-
nomen:Während bundesweit schätzungsweise 4 Erkrankte auf 100.000 Einwohner kommen, sind es in Berlin 19, gefolgt von Köln mit 18 und München mit 16 Infizierten. Die überwiegende Mehrheit der Männer $(82 \%)$ infiziert sich bei homosexuellen Kontakten, während Prostitution für die Übertragung heute kaum noch eine Rolle spielt. 